\title{
Combined therapy with inhaled nitric oxide and intravenous epoprostenol (prostacyclin) for critical pulmonary perfusion after the Fontan procedure
}

\author{
Kagami Miyaji, MD, Nobuhiro Nagata, MD, Takashi Miyamoto, MD, and Kazuo Kitahori, MD, Yokohama, Japan
}

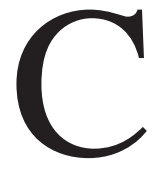

linical studies have demonstrated that inhaled nitric oxide (NO), even in low doses, can reduce elevated pulmonary artery pressure and pulmonary vascular resistance in infants and children with severe pulmonary hypertension after cardiac operations without relevant negative side effects on systemic circulation. ${ }^{1}$ However, several studies have observed a rebound effect after abrupt discontinuation of NO. This rebound effect leads to pulmonary vasoconstriction and deterioration of oxygenation. ${ }^{2}$ On the other hand, intravenous epoprostenol (prostacyclin) is considered a potential pulmonary vasodilator for severe pulmonary hypertension. A synergistic effect of intravenous epoprostenol and inhaled NO has been reported after cardiopulmonary bypass. ${ }^{3}$

\section{Clinical Summaries}

Between March 2000 and February 2001, a total of 3 patients needed inhaled NO therapy after the Fontan procedure. In 2 of these 3 cases, discontinuation of inhaled NO resulted in worsening of the cardiorespiratory state, so combined therapy with inhaled NO and intravenous epoprostenol was applied.

PATIENT 1. The patient was a boy aged 2 years, 11 months with the diagnosis of pulmonary atresia with intact ventricular septum and hypoplastic right ventricle. He underwent a modified Fontan procedure (extracardiac total cavopulmonary connection with an 18-mm polytetrafluoroethylene graft). The patient's hemodynamic parameters were stable with superior and inferior vena caval pressure (measured as central venous pressure [CVP]) of $11 \mathrm{~mm}$ $\mathrm{Hg}$ and common atrial pressure (measured as left atrial pressure [LAP]) of $4 \mathrm{~mm} \mathrm{Hg}$. Six hours after the operation the LAP decreased to $3 \mathrm{~mm} \mathrm{Hg}$ and the CVP increased $15 \mathrm{~mm} \mathrm{Hg}$, so that the transpulmonary pressure gradient (CVP-LAP) was increased to $12 \mathrm{~mm} \mathrm{Hg}$. Inhaled NO therapy at $2.5 \mathrm{ppm}$ was then started, and the patient's hemodynamic status improved significantly (CVP decreased to $11 \mathrm{~mm} \mathrm{Hg}$ and CVP-LAP to $7 \mathrm{~mm} \mathrm{Hg}$ ). After 12 hours of stable hemodynamic status, we started weaning the pa-

From the Department of Cardiovascular Surgery, Kanagawa Children's Medical Center, Yokohama, Japan.

Received for publication June 25, 2002; accepted for publication July 10, 2002.

Address for reprints: Kagami Miyaji, MD, Department of Cardiovascular Surgery, Kanagawa Children's Medical Center, Yokohama, Japan Mutsukawa 2-138-4, Minami-ku, Yokohama, Japan 232-0066 (E-mail: kagami111@aol.com).

J Thorac Cardiovasc Surg 2003;125:437-9

Copyright (C) 2003 by The American Association for Thoracic Surgery $0022-5223 / 2003 \$ 30.00+0$

doi: $10.1067 / \mathrm{mtc} .2003 .199$ tient from inhaled NO by decreasing NO concentration by $1.0 \mathrm{ppm}$ every hour and finally discontinuing inhaled NO. Fifteen minutes after discontinuation, the patient's systemic arterial pressure was unchanged; however, CVP-LAP increased from 6 to $10 \mathrm{~mm} \mathrm{Hg}$ (CVP increased from 12 to $14 \mathrm{~mm} \mathrm{Hg}$ and LAP decreased from 6 to $4 \mathrm{~mm} \mathrm{Hg}$ ). The patient's $\mathrm{Po}_{2}$ significantly decreased from 94.8 $\mathrm{mm} \mathrm{Hg}$ to $64.9 \mathrm{~mm} \mathrm{Hg}$. Inhaled $\mathrm{NO}$ at $2.5 \mathrm{ppm}$ was then restarted, and the CVP-LAP returned to $6 \mathrm{~mm} \mathrm{Hg}$ and the $\mathrm{Po}_{2}$ increased to $90.1 \mathrm{~mm} \mathrm{Hg}$. Intravenous epoprostenol at an initial dose of 2 $\mathrm{ng} / \mathrm{kg} / \mathrm{min}$ was started, increasing incrementally in steps of 2 $\mathrm{ng} / \mathrm{kg} / \mathrm{h}$ to a dose of $8 \mathrm{ng} / \mathrm{kg} / \mathrm{min}$. During therapy with intravenous epoprostenol at $8 \mathrm{ng} / \mathrm{kg} / \mathrm{min}$, inhaled NO was discontinued. This time systemic arterial pressure, CVP, LAP, and CVP-LAP were unchanged, and $\mathrm{PO}_{2}$ decreased slightly from $89.6 \mathrm{~mm} \mathrm{Hg}$ to 76.6 $\mathrm{mm} \mathrm{Hg}$ (arterial oxygen saturation from $97.4 \%$ to $96.2 \%$; Figure 1). The inhaled NO was successfully discontinued, and 2 hours later the patient was extubated. The intravenous epoprostenol was decreased by $2 \mathrm{ng} / \mathrm{kg}$ every 12 hours and discontinued completely 85 hours after extubation.

PATIENT 2. The patient was a 4-year-old girl with a diagnosis of univentricular heart (right ventricular type), pulmonary stenosis, and double-outlet right ventricle. She underwent a fenestrated Fontan procedure (extracardiac total cavopulmonary connection with $18-\mathrm{mm}$ polytetrafluoroethylene graft with $4-\mathrm{mm}$ polytetrafluoroethylene graft fenestration). After bypass the patient remained in hemodynamically stable condition with a CVP of 13 $\mathrm{mm} \mathrm{Hg}$ and an LAP of $5 \mathrm{~mm} \mathrm{Hg}$. Two hours after the operation the patient had a junctional tachycardia (heart rate $>170$ beats/min), her LAP decreased to $3 \mathrm{~mm} \mathrm{Hg}$, her CVP increased to $17 \mathrm{~mm} \mathrm{Hg}$, and her CVP-LAP increased to $14 \mathrm{~mm} \mathrm{Hg}$. Inhaled NO therapy was then started at $2.5 \mathrm{ppm}$, and the patient's hemodynamic status improved (CVP decreased to $12 \mathrm{~mm} \mathrm{Hg}$ and CVP-LAP decreased from 14 to $8 \mathrm{~mm} \mathrm{Hg}$ ). On the sixth postoperative day, cineangiography showed total occlusion of the inferior vena cava and total cavopulmonary connection conduit because of thrombosis. Thrombectomy of the inferior vena cava and total cavopulmonary connection conduit and revision of fenestration (5- $\mathrm{mm}$ polytetrafluoroethylene graft) were performed. The patient's hemodynamic condition restabilized, with a CVP of $15 \mathrm{~mm} \mathrm{Hg}$ and an LAP of 7 $\mathrm{mm} \mathrm{Hg}$. In the unit inhaled $\mathrm{NO}$ was given at the same dose before surgery. After 12 hours of stable hemodynamic status, we started weaning the patient from inhaled NO by decreasing the NO concentration by $1.0 \mathrm{ppm}$ every hour and finally discontinuing inhaled NO. Fifteen minutes after discontinuation, systemic arterial pressure was unchanged; however, CVP-LAP had increased from 7 to $10 \mathrm{~mm} \mathrm{Hg}$ (CVP from 15 to $16 \mathrm{~mm} \mathrm{Hg}$ and LAP from $8 \mathrm{~mm} \mathrm{Hg}$ to $6 \mathrm{~mm} \mathrm{Hg}$ ). Her $\mathrm{Po}_{2}$ significantly decreased from 78.1 $\mathrm{mm} \mathrm{Hg}$ to $57.7 \mathrm{~mm} \mathrm{Hg}$. At that point inhaled $\mathrm{NO}$ was restarted at $2.5 \mathrm{ppm}$, and the CVP-LAP decreased to $6 \mathrm{~mm} \mathrm{Hg}$ and the $\mathrm{Po}_{2}$ 

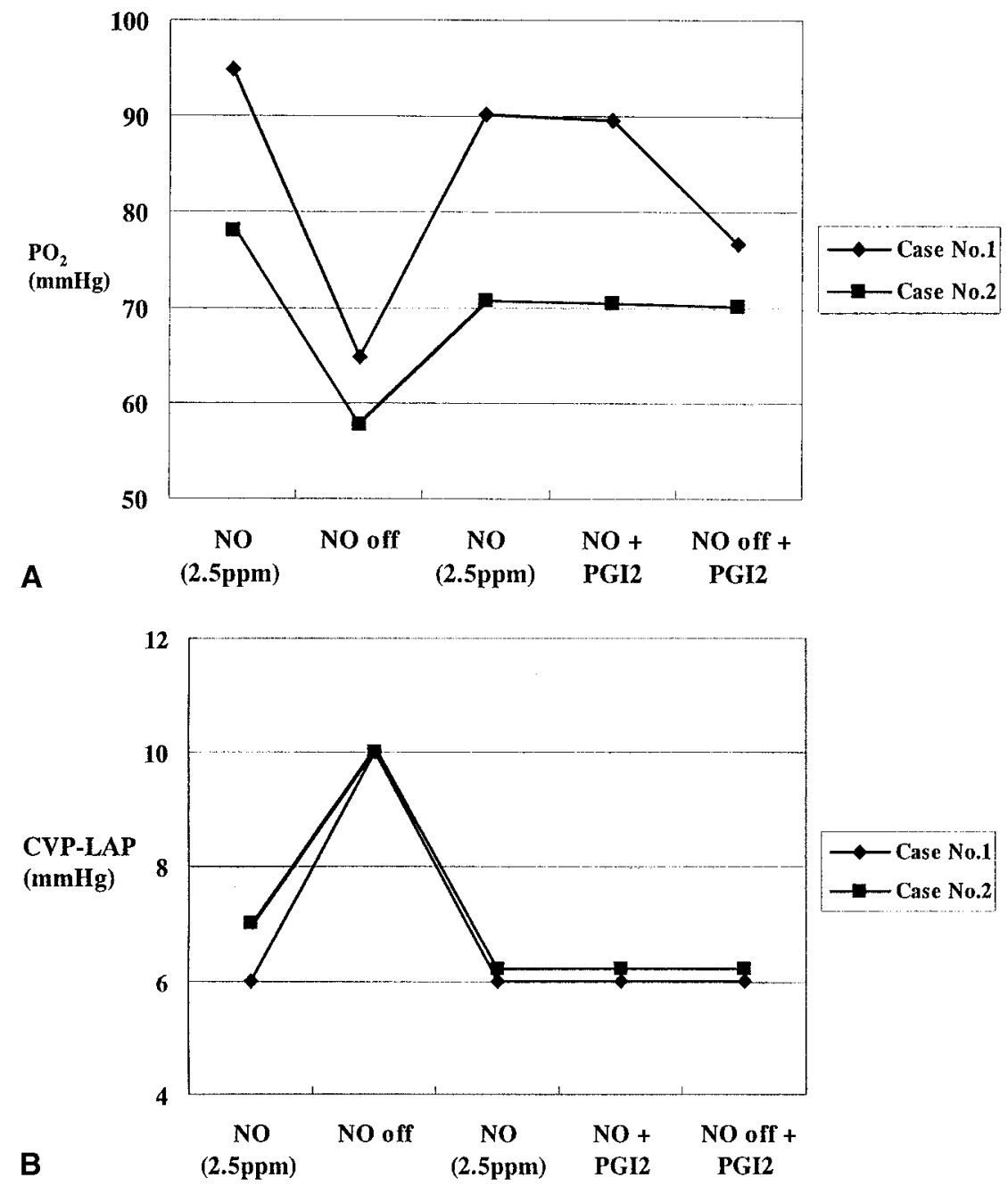

Figure 1. Time courses of $\mathrm{PO}_{2}$ (A) and CVP-LAP (B) in 2 patients. PGI2, Intravenous prostacyclin (epoprostenol).

increased to $70.7 \mathrm{~mm} \mathrm{Hg}$. Intravenous epoprostenol was started at an initial dose of $2 \mathrm{ng} / \mathrm{kg} / \mathrm{min}$, increasing to a dose of $6 \mathrm{ng} / \mathrm{kg} / \mathrm{min}$. During the intravenous epoprostenol therapy, inhaled NO was discontinued. Systemic arterial pressure, CVP, LAP, CVP-LAP, and $\mathrm{PO}_{2}$ remained unchanged (Figure 1), so inhaled NO was successfully discontinued. The intravenous epoprostenol was discontinued 66 hours after the discontinuation of NO, without any complications.

\section{Discussion}

Postoperative morbidity and mortality after Fontan-type operations are mainly related to low cardiac output associated with high CVP values as a result of elevated pulmonary vascular resistance. In the early postoperative period, pulmonary vascular resistance is most labile because of pulmonary endothelial dysfunction after cardiopulmonary bypass. Inhaled NO acts only locally in the adjacent pulmonary smooth muscle cell, producing selective pulmonary vasodilation. Although inhaled NO has this unusual property, the use of this unstable gas has been limited under mechanical venti- lation. The most serious complications of inhaled NO therapy are rebound pulmonary hypertension ${ }^{2}$ and rebound oxygen desaturation, ${ }^{3}$ along with coagulation inhibition and methemoglobinemia. Pulmonary vasodilation achieved by the delivery of large doses of exogenous NO could provoke secondary production or activation of vasoconstrictors. With the short half-life NO, abrupt discontinuation could create a brief period of unobstructed vasoconstriction until stimulation of endogenous vasodilators or a change in the stimulus for vasoconstriction achieved a new balance of vasomotor tone.

Exogenous epoprostenol administered intravenously is accepted as one of the pulmonary vasodilators of choice for patients with severe pulmonary hypertension after heart operations. Epoprostenol is naturally occurring endogenous vasodilator produced by the endothelium. Like all intravenous pulmonary vasodilators, however, it is limited in its use by lack of specificity for pulmonary vasculature, which may result in systemic hypotension. Goldman and coworkers ${ }^{4}$ reported that an improvement in oxygenation was observed only with inhaled NO and not with epopro- 
stenol in treating children with severe pulmonary hypertension after cardiac surgery. Inhaled NO relieved the hypoxia-induced vasoconstriction and improved ventilation-perfusion mismatch, which intravenous epoprostenol aggravated. On the other hand, Hermon and colleagues ${ }^{3}$ reported that intravenous epoprostenol mitigates the inhaled NO rebound effect of oxygenation deterioration in patients with pulmonary hypertension. Our preliminary experience showed that combined therapy with inhaled NO and intravenous epoprostenol was effective in preventing the critical rebound after discontinuation of inhaled NO therapy. The intravenous administration of epoprostenol was discontinued without any rebound effects or complications.

\section{References}

1. Miller OI, Clermajer DS, Deanfield JE, Macrae DJ. Very-low-dose inhaled nitric oxide: a selective pulmonary vasodilator after operations for congenital heart disease. J Thorac Cardiovasc Surg. 1994;108: 487-94.

2. Atz AM, Adatia I, Wessel DL. Rebound pulmonary hypertension after inhalation of nitric oxide. Ann Thorac Surg. 1996;62:1759-64.

3. Hermon M, Golej J, Burda G, Marx M, Trittenwein G, Pollak A. Intravenous prostacyclin mitigates inhaled nitric oxide rebound effect: a case control study. Artif Organs. 1999;23:975-8.

4. Goldman AP, Delius RE, Deanfield JE, Macrae DJ. Nitric oxide is superior to prostacyclin for pulmonary hypertension after cardiac operation. Ann Thorac Surg. 1995;60:300-6.

\section{Targeted}

The Journal of Thoracic and Cardiovascular Surgery gives you two tables of contents. The condensed table of contents tells you at a glance what topics and authors are presented each month. The expanded table of contents gives you a brief abstract of each article. You select only those articles of most interest to you for further reading. 